\title{
The Realization of Complaint Strategies among Iranian Female EFL Learners and Female Native English Speakers: A Politeness Perspective
}

\author{
Atefeh Eshraghi ${ }^{1} \&$ Mohsen Shahrokhi ${ }^{1}$ \\ ${ }^{1}$ Department of English, Shahreza Branch, Islamic Azad University, Shahreza, Isfahan, Iran \\ Correspondence: Mohsen Shahrokhi, Department of English, Shahreza Branch, Islamic Azad University, Isfahan, \\ Iran. E-mail: Shahrokhi1651@yahoo.com
}

Received: January 18, 2016 Accepted: February 21, 2016 Online Published: March 28, 2016

doi:10.5539/ijel.v6n2p9 URL: http://dx.doi.org/10.5539/ijel.v6n2p9

\begin{abstract}
Speech acts are interesting areas of research and there has been much research on speech acts. Complaint is a type of speech act and how to use it in interaction is important to EFL learners. The complaint strategies employed by Iranian female EFL learners and female English native speakers were compared in this study. Also, the effects of contextual variables (Social distance and Social power) on the choice of complaint strategies by Iranian female EFL learners and female native English speakers were studied in this research. Thirty Iranian female EFL learners and thirty female native English speakers participated in this study. The two instruments which were used in this study included Oxford Placement Test (OPT) and Discourse Completion Test (DCT). The (DCT), as an open-ended questionnaire was administrated to them to elicit complaint speech acts. Then, the collected data were analyzed according to a modified taxonomy of complaint strategies proposed by Trosoborg (1995). The results indicated that there was a significant difference between Iranian female EFL learners and female native English speakers in terms of using complaint strategies. Iranian female EFL learners used indirect complaint, while female native English speakers used the direct complaint more frequently; and contextual variables had a great influence on complaint strategy choice by participants of two groups.
\end{abstract}

Keywords: complaint strategies, social distance, social power, DCT, female English native speakers, Iranian female EFL learners

\section{Introduction}

\subsection{Background to the Study}

During recent years, communicative competence has been paid more attention in the field of second/foreign language teaching and learning. According to Heyms (1972), "communicative competence" refers to the level of language learning that enables language users to convey their massages to others and to understand others' messages within specific contexts. Heyms (1972) states that second language learners must learn to speak not only grammatically, but also "appropriately" to achieve communicative goals.

The concept of "appropriateness" is explained by Novick (2000) who postulates that second or foreign language learners must acquire not only linguistic rules such as morphology, syntax, phonology and vocabulary, but also they must acquire socio-cultural rules of language use. Tank (2002) states speakers who seem fluent in a foreign language due to their command of the grammatical rules of that language and its vocabulary may still lack pragmatic competence as a component of communicative competence, and as a result they may not be able to produce language that is socially and culturally appropriate.

Pragmatic competence is "an understanding of the relationship between form and context that enables us, accurately and appropriately, to express and interpret intended meaning" (Murray, 2010, p. 293). Speech acts have traditionally been regarded as one of the major areas of pragmatic studies (Levinson, 1983). The theory of speech acts was first proposed by Austin (1962) and later developed by Searle (1969). Austin (1962) views "saying something" as "doing" things, performing actions such as paying compliments, making requests, extending invitations and others.

Speech acts are produced within a wider context, which is called a "speech event" and "it is the nature of speech 
event that determines the interpretation of an utterance as performing a particular speech act" (Yule, 1996, p. 125). The context in which a speech act is performed embeds different variables -for instance social powers social distance, and degree of directness- that influence the way a speech act is realized. "The social distance between the interlocutors is an indication of how well the speaker and the hearer know one another. Social distance has a binary value of (+SD), where the interlocutors do not know one another well, and (-SD), where the interlocutors know one another well" (Shahrokhi \& Jan, 2012, p. 693). Moreover, "the social power is the relative social dominance of one of the interlocutors on the other one; social dominance has a ternary value, namely $(\mathrm{S}>\mathrm{H})$ where the speaker dominates the hearer, $(\mathrm{S}=\mathrm{H})$ where the speaker and the hearer are equal, and $(\mathrm{S}<\mathrm{H})$ where the speaker is dominated by the hearer" (Shahrokhi \& Jan, 2012, p. 693). Searle (1976) claims, speech acts can be performed directly and indirectly. Direct speech acts refer to the performance of certain acts in which the speaker means what he literally says, and indirect speech acts refer to performative acts in which the speaker means more or something other than what is uttered. Searle (1976) proposes that all speech acts, except performatives are indirect to some degree.

Trosborg (1995, p. 174) defines a complaint as "an illocutionary act in which the speaker expresses his/her disapproval, negative feelings etc. towards the state of affairs described in the proposition and for which he/she holds the hearer responsible, either directly or indirectly."

Brown and Levinson (1987) state that all type of speech acts are face threatening in nature either to the speaker or to the hearer. They defined "face" as "the public self-image that every members wants to claim for himself, consisting of two related aspects: (a) negative face ... [and] (b) positive face" (Brown \& Levinson 1987, p. 61). They referred to positive face as one's wish to be liked and negative face as one's desire not to be impeded and imposed by others. One feature of complaining that is generally agreed on by researchers is that the speech of complaint involves a face-threatening act (Sauer, 2000; Murphy \& Neu, 1996; Olshtain \& Weinbach, 1987). When the complaint is performed directly, that is, when the speaker makes complaints about someone or something that is present in the speech act scene (Sauer, 2000; Boxer, 1993), the speech act of complaining is inherently face-threatening to the hearer. Normally, complaint can threaten the addressee's positive face; therefore, it requires speakers to be competent enough in performing a complaint.

\subsection{Statement of the Problem}

One of the important issues that language users should bear in mind in communication with speakers of another language is their attention to pragmatic norms and behaviors that are different between them. These differences in cross-cultural communication may lead to misinterpretation, miscommunication and breakdown in communication, if ignored. Cross-cultural communication is defined as the face-to-face interaction between people from different cultural backgrounds including empirical studies that investigate various speech acts.

It is believes that learning a language is indeed learning how to communicate in that language, and a successful communication between interlocutors rests upon proper speech acts realization (Zhao \& Throssel, 2011). Therefore, successful communication in a target language requires not only the knowledge of grammar and vocabulary but also pragmatic competence and knowledge about the culture of the target language. One important aspect of pragmatic competence is understanding and realizing speech acts and their appropriateness in a given situation (Cheng, 2005). Native speakers of English use many types of speech acts (apology, request, compliment, complaint) and it is important for foreign language learners of English to be able to understand them.

Previous studies have shown that even EFL learners with sufficient linguistic knowledge make mistakes in real life communication with foreigners or may fail to use appropriate pattern of speech acts. They are good at reading and writing with sufficient knowledge of English grammar and vocabulary, but they fail in communication with foreigners. Iranian learners of English may fail to use appropriate pattern of speech acts and may not know when it is appropriate to express certain feelings and to what degree such feelings should be conveyed on a given occasion, especially in situations where negative feelings are involved, such as complaining.

A number of differences between English and Persian in the area of speech acts may be linked with different cultural values and beliefs. It is necessary to learn how to understand and realize language that is appropriate for the situations in which one is functioning, because failure to do so may cause misunderstandings and miscommunications. Complaints may be different from culture to culture; consequently, identifying these differences may lead to better communication.

The current study investigated English complaint speech acts strategies and compared them with those of Iranian EFL learners. Adopting a gender perspective, the study controlled the gender of participants to check the impact 
of female gender on the realization of complaint speech acts.

Boxer (1993) explained social distance has an influence on complaint behaviors. Therefore, another concern of this study was the possible effect of contextual variables (social distance and social power) on the complaint strategies of Iranian EFL learners and native English speakers in different situations. The study aimed at checking whether Iranian female learners' pragmatic development matches those of native English speakers as far as the perception of contextual variables are concerned when realizing a complaint speech act.

\subsection{Research Question}

In order to address the concerns of the current study the following question was raised.

RQ: Is there any significant difference between Iranian female EFL learners and female native English speakers in terms of using complaint strategies with regard to contextual variables?

\subsection{Research Hypothesis}

Based on the above question the following hypothesis was formulated.

$\mathrm{H}_{0}$ : There is no significant difference between Iranian female EFL learners and female native English speakers in terms of using complaint strategies with regard to contextual variables.

\section{Method}

\subsection{Participants}

The intended population of this study comprised Iranian female university students. The researchers selected some 30 Iranian female EFL learners whose ages were between 18 and 25 years old from TEFL students of Shahreza Azad University, Shahreza, Isfahan, Iran. They were selected based on their OPT score. The OPT was used to select a homogenized sample of participants who were at upper intermediate level of English proficiency. The second group included 30 female native English speakers and they were selected non-randomly. The native English speakers' ages were between 19 and 31 years old and they had university degree. The native English speakers were contacted by a research assistant who was a relative of one of the researchers and their consent was obtained to make sure they would participate in the study.

\subsection{Instruments}

Two instruments which were used in this study included Oxford Placement Test (OPT) and Discourse Completion Test (DCT).

Oxford Placement Test (OPT) was used to select homogeneous Iranian female EFL learners in terms of English proficiency from among Iranian TEFL students. The OPT consisted of listening and grammar sections. In the listening section test takers were asked to choose the correct word which they heard in short sentences from two choices and in the grammar section they were asked to read the stem with a blank and choose one of the three options for the blank.

Another data collection instrument was an open-ended questionnaire in the form Discourse Completion Test (DCT) (See Appendix A). An open ended questionnaire was used in this study because it could elicit the target speech acts, e. i. complaint, from among the participants in relation to their interactions in real situations.

Controlled methods such as DCTs allow for large amounts of data to be collected quickly; they provide information about the kinds of semantic formulas that learners use to realize different illocutionary acts, and reveal the social factors that learners think are important for speech act performance (Ellis, 1994). Nurani (2009) has pointed out DCT is a proper method which provides stereotypical responses for socially appropriate response; moreover, it allows researchers to collect data in a short period. This method is also easy for comparing responses collected from among native speakers with those of non-native speakers statistically (Blum-Kulka, House \& Kasper, 1989).

The DCT in this study included 6 situations different in terms of contextual variables. The researchers consulted a few EFL professors and native English speakers to obtain the conformity validity of the DCT.

The participants were required to write down their verbal reactions to situations explained in the DCT and respond exactly the way they would respond in their daily interactions. In addition, the DCT was sent and distributed among the native English speakers, who were from USA, by a research assistant via e-mail. The DCTs were collected and returned again by the research assistant.

\subsection{Data Analysis Framework}

Trosborg (1995) outlines four main complaint categorizes which were similar to those offered by Oleshtan and 
Weinbach (1987). Trosoborg divides four categories into eight sub categories.

\subsubsection{No Explicit Reproach}

This category has one sub-category, namely hints. As a complaint is an illocutionary face threating act, the speaker may use the hinting strategies to avoid a conflict. This strategy is considered the most indirect since the speaker dose not directly say something is bad.

- Hint

Don't see much of you these days, do I? (Trosborg, 1995).

\subsubsection{Expression of Annoyance or Disapproval Category}

This category is used for expressing a complainer's negative judgment of a complainee's act. It consists of two strategies namely annoyance and ill consequences. Compared to category 1, it performs a higher level of face-threat.

- $\quad$ Consequences

I have already spent ten minutes oh, quarters of an hour I think it was, cleaning up the bathroom itself (Trosborg, 1995).

- Annoyance

There's a horrible dent in my car. Oh, dear I have just bought it (Trosborg, 1995).

\subsubsection{Accusation}

This category is composed of two strategies, namely direct and indirect, which aim to convey a particular complaint message in different ways. Direct accusations are straight statement, while indirect accusations are ambiguous ones.

- Indirect

You borrowed my car last night, didn't you? (Trosborg, 1995).

- $\quad$ Direct

Did you happen to bump into my car? (Trosborg, 1995).

\subsubsection{Blame}

This is the highest face-threatening level of complaint strategy. Speakers complain directly and aggressively and may use face threating acts. This category include three strategy namely modified blame, explicit blame (behavior) used for blaming bad action, and explicit blame (person) used for blaming an irresponsible person.

- $\quad$ Explicit blame (behavior)

How on earth did you manage to be stupid? (Trosborg, 1995).

- $\quad$ Explicit blame (person)

Oh no, not again! You really are thoughtless. Bloody fool! You've done it again!

- Modified blame

Honestly, couldn't you have been more careful? Yes should take more care with other people's car? (Trosborg, 1995).

The analytical framework of Trosborg was used in this study to understand how Iranian female EFL learners and native English speakers make complaint based on contextual variables.

\subsection{Statistical Analysis}

Both descriptive statistics (frequency, percentage) and inferential statistics were used through the software Statistics Package for Social Sciences (SPSS). Once the descriptive statistics of the data were obtained, Chi-square test was used to compare the frequencies of complaint strategies realized by Iranian EFL learners and female native English speakers.

\section{Results}

The data gathered through the OPT and DCT provided the researchers with adequate and acceptable information based on the participants' ideas. The OPT was used in order to select homogenized sample of participants (Iranian female EFL learners) who were upper intermediate. So, 30 of Iranian female EFL learners whose score were between 80 and 89 were selected for this study. Different strategies for expressing complaint in both EFL 
and native contexts were evaluated and pinpointed by 60 participants, including 30 non-native and 30 native participants. The results obtained are explained based on situations in the DCT.

\subsection{Situation 1}

The first situation that was looked into was as follows: you are a university professor. You have lent your book to one of your students in order for her to deliver a lecture based on the book. Now, she has returned your book but some of pages have been damaged. How will you complain?

As it can be seen in Table 1, Explicit blame on person and indirect accusation were the first and second most frequently used strategies by Iranian female EFL learners in this situation.

Explicit blame on person example: If I knew you are so carefree, I would never lend it to you.

Native English speakers employed Explicit blame on behavior and Annoyance expression as the first and second most frequently used strategies for this situation.

Explicit blame on behavior example: when something is lent to somebody, the person should take care of it carefully.

The findings also indicated that consequence expression and Explicit blame on behavior were the third and fourth frequently used strategies by Iranian female EFL learners. The results also showed that direct accusation and Consequence expression were the third and fourth frequently used strategy by English native speakers. Moreover, for both native English speakers and Iranian EFL learners the strategy of Hint giving was the least frequently used strategy.

Table 1. Results for situation 1

\begin{tabular}{lllll}
\hline Strategy & \multicolumn{2}{l}{ Non-native English Speakers } & \multicolumn{2}{l}{ Native English Speaker } \\
& Frequency & Percent & Frequency & Percent \\
\hline Hint giving & 0 & $0 \%$ & 0 & $0 \%$ \\
Annoyance Expression & 1 & $3.11 \%$ & 8 & $22.40 \%$ \\
Consequences Expression & 5 & $19.75 \%$ & 3 & $15.60 \%$ \\
Direct Accusation & 1 & $3.11 \%$ & 5 & $18.80 \%$ \\
Indirect Accusation & 7 & $21.40 \%$ & 2 & $7.55 \%$ \\
Modified Blame & 2 & $8.10 \%$ & 1 & $6.30 \%$ \\
Explicit Blame on Behavior & 3 & $17.20 \%$ & 10 & $24.80 \%$ \\
Explicit Blame on Person & 11 & $25.55 \%$ & 1 & $6.30 \%$ \\
\hline
\end{tabular}

\subsection{Situation 2}

The second situation for which the participants' viewpoints were sought was as follows: Suppose you are a professor. While are teaching, you understand a student from another major is sitting in your class without getting permission and she is disturbing your class. How will you complain?

Table 2. Results for situation 2

\begin{tabular}{|c|c|c|c|c|}
\hline \multirow[t]{2}{*}{ Strategy } & \multicolumn{2}{|c|}{ Non-native English Speakers } & \multicolumn{2}{|c|}{ Native English Speaker } \\
\hline & Frequency & Percent & Frequency & Percent \\
\hline Hint giving & 3 & $5.11 \%$ & 0 & $0 \%$ \\
\hline Annoyance Expression & 4 & $20.35 \%$ & 5 & $19.40 \%$ \\
\hline Consequences Expression & 0 & $0 \%$ & 0 & $0 \%$ \\
\hline Direct Accusation & 2 & $5.11 \%$ & 3 & $16.80 \%$ \\
\hline Indirect Accusation & 7 & $22.10 \%$ & 2 & $13.55 \%$ \\
\hline Modified Blame & 0 & $0 \%$ & 0 & $0 \%$ \\
\hline Explicit Blame on Behavior & 10 & $24.70 \%$ & 7 & $23.80 \%$ \\
\hline Explicit Blame on Person & 4 & $19.55 \%$ & 13 & $28.80 \%$ \\
\hline
\end{tabular}

As it can be seen in Table 2, Explicit blame on behavior was the most frequently used strategy by Iranian female EFL learners.

Explicit blame on behavior example: Coming to a class without prior permission is not appropriate for an academic person. 
Indirect accusation and Annoyance expression strategies were the second and third frequently used strategies by this group of speakers and Consequence expression and modified blame strategies were the least frequently used strategies by non-native English speakers. The table also shows that as far as Native English speakers were concerned, Explicit blame on person was the most frequently used strategy in such a hypothetical situation and after that, Explicit blame on behavior was the most preferred strategy for them.

Explicit blame on person example: Why did not you ask me to enter the class?

Finally, the table also reveals that none of the Native English speakers selected Hint giving, Consequence expression, and Modified blame strategies for complaint expression in this context.

\subsection{Situation 3}

As for situation 3 (You lent your book to your friend four days ago. You have told her that she should return it soon because you need it. Tomorrow you have an exam and you need the book. You have called her but she has not returned it yet. How will you complain when you see her?), Table 3 presents the findings. According to the table, Explicit blame on person was the most often used strategy by both non-native English speakers and native English speakers.

Explicit blame on person example: You are such an irresponsible person.

The second frequently used strategy by Non-native English speakers was Direct accusation and by English native speakers was also Direct accusation. The findings also indicated that non-native speakers used Explicit blame on behavior, Annoyance expression, and Indirect accusations were the other preferred strategy for Iranian speakers. Moreover, Annoyance expression and Explicit blame on behavior were the third and fourth frequently used strategies for complaining in this context.

Table 3. Results for situation 3

\begin{tabular}{lllll}
\hline Strategy & \multicolumn{2}{l}{ Non-native English Speakers } & \multicolumn{2}{l}{ Native English Speaker } \\
& Frequency & Percent & Frequency & $0 \%$ \\
& 0 & $0 \%$ & 0 & $23.77 \%$ \\
\hline Hint giving & 5 & $17.77 \%$ & 6 & $0 \%$ \\
Annoyance Expression & 0 & $0 \%$ & 0 & $27.90 \%$ \\
Consequences Expression & 7 & $23.70 \%$ & 7 & $0 \%$ \\
Direct Accusation & 5 & $17.77 \%$ & 0 & $0 \%$ \\
Indirect Accusation & 0 & $0 \%$ & 0 & $19.30 \%$ \\
Modified Blame & 5 & $17.77 \%$ & 3 & $30.60 \%$ \\
Explicit Blame on Behavior & 8 & $25.25 \%$ & 14 & \\
Explicit Blame on Person & & & & 0 \\
\hline
\end{tabular}

\subsection{Situation 4}

The fourth situation that was tested was: You are waiting in a line to buy a concert ticket. You have been waiting for a long time. Suddenly, a person cuts in line in front of you. How will you complain? The obtained results for this situation are presented in Table 4. As it is obvious from the table, Direct accusation strategy is the most often used strategy by non-native English speakers in this hypothetical context.

\section{Direct accusation example: You are an inconsiderate person}

These speakers then prefer to employ Explicit blame on person and Indirect accusation for the same situation. In a similar vein, native English speakers have equally preferred to make use of Explicit blame on person and Direct accusation strategies for complaining on such a situation. Moreover, not even one of the two groups of participants selected hint giving strategy for this situation.

Explicit blame on person example: cannot you understand that you should stay in line as others do? 
Table 4. Results for situation 4

\begin{tabular}{|c|c|c|c|c|}
\hline \multirow[t]{2}{*}{ Strategy } & \multicolumn{2}{|c|}{ Non-native English Speakers } & \multicolumn{2}{|c|}{ Native English Speakers } \\
\hline & Frequency & Percent & Frequency & Percent \\
\hline Hint giving & 0 & $0 \%$ & 0 & $0 \%$ \\
\hline Annoyance Expression & 4 & $13.85 \%$ & 4 & $17.54 \%$ \\
\hline Consequences Expression & 0 & $0 \%$ & 1 & $4 \%$ \\
\hline Direct Accusation & 9 & $25.55 \%$ & 10 & $28.10 \%$ \\
\hline Indirect Accusation & 5 & $16.67 \%$ & 0 & $0 \%$ \\
\hline Modified Blame & 1 & $8 \%$ & 2 & $8 \%$ \\
\hline Explicit Blame on Behavior & 5 & $16.67 \%$ & 3 & $15.35 \%$ \\
\hline Explicit Blame on Person & 6 & $20.15 \%$ & 10 & $28.10 \%$ \\
\hline
\end{tabular}

\subsection{Situation 5}

In the fifth hypothetical situation, a more close relationship is concerned: You are an employee in a company. The boss, who is an old friend of you, has not paid your salary for two months. How will you complain? The pertinent findings are presented in Table 5. According to the table, Iranian female EFL learners mostly like to use indirect strategies especially Hint giving and then Annoyance expression to make their boss notice lack of salary payment.

Hint giving example: I have no money to take my child to hospital.

Female native English speakers also prefer the same strategies but in reverse order meaning that they mostly prefer the Annoyance expression and then Hint giving strategy.

Annoyance expression example: I do not know how to pay for my broken refrigerator.

Table 5. Results for situation 5

\begin{tabular}{lllll}
\hline Strategy & \multicolumn{2}{l}{ Non-native English Speakers } & \multicolumn{2}{l}{ Native English Speakers } \\
& Frequency & Percent & Frequency & Percent \\
\hline Hint giving & 11 & $28.40 \%$ & 8 & $24.47 \%$ \\
Annoyance Expression & 8 & $23.15 \%$ & 11 & $31.15 \%$ \\
Consequences Expression & 5 & $21.95 \%$ & 1 & $7.90 \%$ \\
Direct Accusation & 0 & $0 \%$ & 0 & $0 \%$ \\
Indirect Accusation & 4 & $16.33 \%$ & 6 & $21.11 \%$ \\
Modified Blame & 2 & $11.50 \%$ & 4 & $16.15 \%$ \\
Explicit blame Behavior & 0 & $0 \%$ & 0 & $0 \%$ \\
Explicit Blame on Person & 0 & $0 \%$ & 0 & $0 \%$ \\
\hline
\end{tabular}

\subsection{Situation 6}

Finally, the sixth hypothetical situation asked in the study instrument was as follows: You are sick and you need to get some sleep. Your new landlord and you have never talked to each other before about making a lot of noise. You have put up with the noise for several days but tonight you feel you should do something. How will you complain?

According to Table 6, in such a situation, Iranian female EFL learners and female native English speakers both tend to make use of Annoyance expression strategy (however with different percentages). After this strategy, Iranian female EFL learners prefer Consequence expression but native English speakers like to use Direct accusation for showing their complaint on this situation.

Annoyance expression example: Last night I could not sleep a wink. 
Table 6. Results for situation 6

\begin{tabular}{lllll}
\hline Strategy & \multicolumn{2}{c}{ Non-native English Speakers } & \multicolumn{2}{c}{ Native English Speakers } \\
& Frequency & Percent & Frequency & Percent \\
\hline Hint giving & 0 & $0 \%$ & 0 & $0 \%$ \\
Annoyance Expression & 12 & $30.46 \%$ & 12 & $33.38 \%$ \\
Consequences Expression & 8 & $22.35 \%$ & 3 & $15.41 \%$ \\
Direct Accusation & 3 & $15.69 \%$ & 7 & $22.73 \%$ \\
Indirect Accusation & 0 & $0 \%$ & 2 & $11.41 \%$ \\
Modified Blame & 0 & $0 \%$ & 0 & $0 \%$ \\
Explicit Blame on Behavior & 5 & $20.20 \%$ & 6 & $18.20 \%$ \\
Explicit Blame on Person & 2 & $12.51 \%$ & 0 & $0 \%$ \\
\hline
\end{tabular}

\subsection{Overall Strategies Use}

Having analyzed and described the obtained findings for each of the six situations, Table 7 below represents the overall use of each strategy by the two groups of the participants. The table shows that as far Iranian female EFL learners are concerned, Annoyance expression is the most frequently used strategy for complaining situations (24.55 \%). Next, Explicit Blame on Person (19.63\%) registered as the most frequent strategy. After that, Indirect accusation and Explicit blame on behavior are equally the third most frequently employed strategies by Iranian female EFL learners (each $14.86 \%$ ). Furthermore, the table also uncovers that Modified blame and Hint giving are the first and second strategies that have been least used by Iranian female EFL learners $(1.11 \%$ and $4.39 \%$ respectively).

Likewise, for the English native female speakers, the Annoyance expression is the most often used complaining strategy (35.18 \%) and then Explicit blame on person and Direct accusation strategies are the second and third frequently used strategies ( $22.13 \%$ and $15.33 \%$ respectively). Finally, it is also understood from the same table that native English speakers are least likely to use Modified blame and Hint giving strategies to express their complaint on different situations ( $1.13 \%$ and $2.21 \%$ respectively).

Table 7. Overall strategy use

\begin{tabular}{lllll}
\hline Strategy & \multicolumn{2}{l}{$\begin{array}{l}\text { Non-native English Speakers } \\
\text { Frequency }\end{array}$} & Percent & \multicolumn{2}{c}{ English Native Speakers } \\
& 14 & $4.39 \%$ & 8 & $2.21 \%$ \\
\hline Hint giving & 34 & $24.55 \%$ & 46 & $35.18 \%$ \\
Annoyance Expression & 18 & $8.94 \%$ & 8 & $2.21 \%$ \\
Consequences Expression & 22 & $12.19 \%$ & 32 & $15.33 \%$ \\
Direct Accusation & 28 & $14.86 \%$ & 12 & $3.86 \%$ \\
Indirect Accusation & 5 & $1.11 \%$ & 7 & $1.13 \%$ \\
Modified Blame & 28 & $14.86 \%$ & 29 & $13.49 \%$ \\
Explicit Blame on Behavior & 31 & $19.63 \%$ & 38 & $22.13 \%$ \\
Explicit Blame on Person & & & & \\
\hline
\end{tabular}

\subsection{Chi-Square Results}

The above-mentioned results and information show the frequency and percentage of each strategy used by the two groups of the participants. However, they do not reveal any exact information as to whether there is any significant difference between the Iranian female EFL learners and female native English speakers in the use of each of the strategies. In other words, it is not possible to make any conclusive conclusion whether the native English speakers and Iranian female EFL learners are significantly different from each other in using complaining strategies or not. To reach such type of finding, a Chi-square test was run and its obtained statistics are shown in Table 8. 
Table 8. Chi-square results for six situations

\begin{tabular}{lllll}
\hline Strategy & Chi-Square & Df & Sig. \\
\hline Hint Giving & 4.16 & 1 & $.04^{*}$ \\
Annoyance Accusation & .36 & 1 & $.03^{*}$ \\
Consequences Expression & 3.06 & 1 & $.01^{*}$ \\
Direct Accusation & 1.14 & 1 & $.02^{*}$ \\
Indirect Accusation & 1.49 & 1 & $.01^{*}$ \\
Modified Blame & 3.87 & 1 & .21 \\
Explicit Blame on Behavior & 2.24 & 1 & .94 \\
Explicit Blame on Person & 1.76 & 1 & $.04^{*}$ \\
\hline
\end{tabular}

Note. * indicates significance at $\mathrm{p} \leq .05$.

According to the table, the Iranian female EFL learners and female native English speakers are significantly different from each other in terms of six strategies of Hint giving, Annoyance expression, Consequence expression, Direct accusation, Indirect accusation, and Explicit blame on person. The table also reveals that in terms of Modified blame and Explicit blame on behavior strategies, the two groups are not significantly different from each other.

\section{Discussion and Conclusion}

The main objective of the current study, as it was stated, was to investigate what kinds of complaining strategies female native English speakers and Iranian female EFL learners employ in order to cope with different complaint contexts. The research hypothesis of the study contends that native English speakers and Iranian female EFL learners act similarly in terms of their complaint strategy preferences. However, based on the obtained results presented in the preceding section, the hypothesis is rejected because the two groups of participants differed significantly from each other in terms of six strategies of Hint giving, Annoyance expression, Consequence expression, Direct accusation, Indirect accusation, and Explicit blame on person, though in terms of two strategies of Modified blame and Explicit blame on behavior strategies, the two groups were not significantly different from each other. Generally, these two groups of participants were significantly different.

The finding might be justified based on different premises. For example, it can be maintained that the two groups might be almost homogeneous in their linguistic competence but not in terms of their pragmatic competence. To put it clearly, female native English speakers and Iranian female EFL learners might have different attitudes and understanding from a complaining situation and accordingly they prefer to make use of different strategies to deal with that specific context. In other words, in addition to "linguistic" competence, learners need to have "pragmatic" competence to be able to understand and communicate meanings and intentions appropriately in their L2 (Li, 2010).

Furthermore, the issue of politeness and understanding it might also be regarded as another reason for the significant difference between the two groups of the participants. That is, the findings of study show that native English speakers generally tend to adopt more direct strategies, compared to non-native ones, to express their complaint. This might be due to their differences in understanding the concept of politeness. In other words, one thing which may justify this difference in the attitudes of native English speakers with those of the other group of the study is the context in which these two groups live. In an Iranian context which is considered as an EFL one, due to the existence of specific cultural and religious norms which are not almost in harmony with the direct realization of complaints in English, complaints is realized more cautiously and indirectly to minimize the face-threatening nature of complaints. In English, it seems, the cultural and religious conditions are not so influencing as it is in the Iranian context.

Finally, social distance and social power might also be other factors affecting the significant difference between the two groups of participants. The results indicated that social status of interlocutor had a great influence on strategy use by participants of two groups.

\section{Implications}

Due to the point that discourse, sociolinguistics, and strategy use are considered as important aspects in learning a foreign or second language and different studies might come up with different findings on them, pedagogically relevant findings need to be treated cautiously. Likewise, the findings of this empirical study are no exception. In order for the findings of this study to be pedagogically valid and applicable, they need to be subjected to replication studies and empirical validation process. It is then and only then that the results and findings can be 
generalized to other populations. The study, however, enjoys a set of implications. First of all, in the light of this research, teachers might be recommended to pay special attention to teaching strategies and especially complaining strategies in which cultural and contextual variables are very important and using wrong strategies might lead to misunderstanding and sometimes a clash in communication. They are encouraged to increase learners' awareness concerning different learning strategies and their effectiveness especially as far as complaining strategies are concerned. Secondly and in line with the first implication, teachers are encouraged to raise their own awareness and consciousness with regard to various types of the strategies so that not only teachers themselves would be more capable in making use of the strategies, but also, they can be more effective in helping their learners increase their ability and awareness in using the strategies appropriately. Besides, since a significant difference between speech act use (specifically complaining strategies) between native and non-native speakers was observed, teachers are expected to make their learners notice the point that using strategies would help them to have a better performance on different situations. Additionally, as findings of the related literature have shown, many factors affect the choice of learning strategies including: age, sex, nationality, degree of awareness, language proficiency, motivation, personality traits, learning context, and learning style (Zare, 2012). As a result, teachers and learners should take all these factors into consideration while teaching complaint strategies.

\section{References}

Austin, J. (1962). How to do things with words. In A. Jaworski \& N. Coupland (Eds.), The discourse reader (pp. 63-75). New York: Routledge.

Bachman, L. (1990). Fundamental considerations in language testing. Oxford: Oxford University Press.

Blum-Kulka, S., House, J., \& Kasper, G. (Eds.). (1989). Cross cultural Pragmatics: Requests and apologies. Norwood, Nj: Ablex.

Boxer, D. (1993). Complaint and commiserating, a speech act view of solidarity in spoken American English. New York: Peter Lang Publishing Inc.

Cheng, S. W. (2005). An exploratory cross-sectional study of interlanguage pragmatic development of expressions of gratitude by Chinese learners of English. A doctoral dissertation, University of Iowa.

Ervin-Tripp, S. (1976). Is Sybli there? The structure of some American English directives. Language insociety, 5(1), 25-66. http://dx.doi.org/10.1017/S0047404500006849

Hymes, D. (1972). On Communicative Competence. In J. B. Pride \& J. Holmes (Eds.), Sociolinguistics Hamondsworth. UK: Penguin Books.

Kasper, G. (1998). Interlanguage pragmatics. In H. Byrnes (Ed.). Learning second and foreign languages (pp. 183-208). New York: The Modern language association of America.

Leech, G. (1983). Principles of pragmatics. Essex: Longman.

Levinson, S. C. (1989). Pragmatics. Cambridge: Cambridge University Press.

Li, E. S. H. (2010). Making suggestions: A contrastive study of young Hong Kong and Australian students. Journal of Pragmatics, 42, 598-616. http://dx.doi.org/10.1016/j.pragma.2009.07.014

Murphy, B., \& Neu, J. (1996). My grade's too low: the speech act set of complaining. In S. M. Gass \& J. Neu (Eds.), Speech acts across cultures: Challenges to communication in second Language (pp. 191-216). Berlin: Mouton de Gruyter.

Murray, N. (2010). Pragmatics, awareness-raising, and the cooperative principle. ELT Journal, 64(3), 293-301. http://dx.doi.org/10.1093/elt/ccp056

Novick, R. (2000). Politeness and rationality. Amsterdam: J. Benjamin Publishing Company.

Nurani, L. (2009). Methodological issue in pragmatic research: Is discourse completion test a reliable data collection instrument? Methodological issue in pragmatic research, 17(8), 667-678.

Oleshtain, E., \& Weinbach, L. (1987). Complaints: a study of speech act behaviour among native and non-native speakers of Hebrew. In J. Verschueren \& Bertucelli-Papi (Eds.), The pragmatic perspective (pp. 195-208). Amsterdame: John Benjamins. http://dx.doi.org/10.1075/pbcs.5.15ols

Sauer, M. (2000). Complaints: A cross-cultural study of pragmatic strategies and linguistic forms. Paper presented at AAAL Conference, Vancouver, Canada.

Searle, J. R. (1969). Speech acts. Cambridge: Cambridge University Press. 
http://dx.doi.org/10.1017/CBO9781139173438

Searle, J. R. (1976). A classification of illocutionary acts. Language in society, 5, 1-23. http://dx.doi.org/10.1017/S0047404500006837

Shahrokhi, M., \& Jan, J. M. (2012). The Realization of Apology Strategies among Persian Males. ProcediaSocial and Behavioral Sciences, 46, 692-700. http://dx.doi.org/10.1016/j.sbspro.2012.05.183

Tank, S. (2002). Speech act sets of refusal and complaint: A comparison of native and non- native English speakers production. Paper presented for TESL 523 Second Language Acquisition Class at American University.

Trosborg, A. (1995). Interlanguage pragmatics: Requests, complaints, apologies. New York: Mouton De Gruyter. http://dx.doi.org/10.1515/9783110885286

Yorio, C. A. (1980). Conventionalized Language Forms and the Development of Communicative Competence. TESOL Quarterly, 14 (4), 433-442. http://dx.doi.org/10.2307/3586232

Yule, G. (1996). Pragmatics. Oxford, England: Oxford University Press.

Zhao, Y., \&Throssell, P. (2011). Speech act theory and its application to EFL teaching in china. The International Journal-Language Society and Culture, 32, 88-95.

\section{Appendix A}

\section{The Discourse Completion Test}

Thank you in advance for your participation in this research and for completing this questionnaire. By completing this questionnaire, you agree that I can use your responses for research purposes and possible publications. All your personal information will remain confidential it the results of this study are presented, written up and/or published.

This questionnaire contains two parts. In part 1, please write down your age and indicate your gender and also write your native language and university major. In part 2 , you should complete the scenarios as explained before.

\section{Part 1}

Age: ..... Gender: ...... Native Language: ..... University major: ...... Degree: ......

\section{Part 2}

There are 6 situations described below. Please read the following descriptions of situations and then write what you would say in each situation.

1: You are a university professor. You have lent your book to one of your students in order for her to give a presentation based on the book. Now, she has returned your book but some of pages have been damaged. How will you complain? $(\mathrm{S}>\mathrm{H},-\mathrm{SD})$

2: Suppose you are a professor. While you are teaching, you understand a student from another major is sitting in your class without getting permission and she is disturbing your class. How will you complain? $(\mathrm{S}>\mathrm{H},+\mathrm{SD})$

3: You lent your book to your friend four days ago. You have told her that she should return it soon because you need it. Tomorrow you have an exam and you need the book. You have called her but she has not returned it yet. How will you complain when you see her? $(\mathrm{S}=\mathrm{H},-\mathrm{SD})$

4: You are waiting in a line to buy a concert ticket. You have been waiting for a long time. Suddenly, a person cuts in line in front of you. How will you complain? $(\mathrm{S}=\mathrm{H},+\mathrm{SD})$.

5: You are an employee in a company. The boss, who is an old friend of you, has not paid your salary for two months. How will you complain? $(\mathrm{S}<\mathrm{H},-\mathrm{SD})$ 
6: You are sick and you need to get some sleep. Your new landlord who you have never talked to before makes a lot of noise. You have put up with the noise for the several days but tonight you feel you should do something. How will you complaint? $(\mathrm{S}<\mathrm{H},+\mathrm{SD})$

\section{Copyrights}

Copyright for this article is retained by the author(s), with first publication rights granted to the journal.

This is an open-access article distributed under the terms and conditions of the Creative Commons Attribution license (http://creativecommons.org/licenses/by/3.0/). 